\title{
Sugar and Spice, Everything Nice? The Festive Season from the Point of View of a Reproductive 3 Toxicologist
}

\author{
Geertje Lewin* \\ Lewin Tox Consulting, Germany
}

Submission: December 20, 2017; Published: February 15, 2018

*Corresponding author: Dr. Geertje Lewin, Lewin Tox Consulting, Steintorfeldstr, 5, 30161 Hannover, Germany, Tel: +49 51199099633 ; Email: g.lewin@web.de

\section{Review}

The festive season, no matter what your religious background, is worldwide a time when we want to gather loved ones around us, celebrating family, friends, peace and freedom. Being a scientist, thankfully, doesn't prevent me from getting these holiday feelings but being a reproductive toxicologist makes it difficult to always separate between work and private life. There, in the following, a short reflection on holiday habits is given.

The festive season is gaining more and more the notion of deeply indulging into food. As much as I love good food, isn't it much more important to rather enjoy the food as to simply consume it in large quantities? The preparation of food, often together with friends and family, the joy to pass the dishes around a large table, laughing and talking while eating and being graceful for what we got, in my opinion is what makes up the spirit of sociability and being together.

When it comes to the end of the year, the scent that is highly associated for me was always cinnamon, no matter if as an ingredient in cookies, cakes, and spiced tea or mulled red wine. The spice is derived from the inner bark of two plant species: Cinnamomum verum (the true cinnamom, native to Sri Lanka) and Cinnamomum cassia (Cassia or Chinese cinnamom, native to China and Southeast Asia). The use of the spice is documented since ancient Egypt, the first medical use in China around 2700 B.C., and all the way to medieval times it was highly priced and affordable to only few. The high demand and the wish to monopolize the trade prompted the European expansion into Asia in the $16^{\text {th }}$ and $17^{\text {th }}$ century. The dried bark of the trees from the Lauraceae family is rich in polyphenols and the essential oils contain about $65-76 \%$ cinnamaldehyde and 4-10\% eugenol [1]. Cinnamon has positive properties at loss of appetite, dyspeptic disorders, it has anti-bacterial properties and is an anti-oxidant. More recently, its insulin-like effect that may help stabilize blood-sugar in patients with type-2 diabetes, mediated by methylhydroxychalcone, was shown. Cinnamon is normally well tolerated, though the essential oils, when applied directly, can cause skin irritation. Precaution has to be applied with large amounts of Cassia cinnamon as the spice contains substantial amounts of coumarin. In especially sensitive persons, even comparatively small quantities of coumarin can cause liver damage. For this reason, it is not advisable to consume large quantities of it over prolonged periods of time. The German Federal Institute for Risk Assessment BfR [2] issued a warning in 2012. The tolerable daily intake (TDI) was derived based on experimental and epidemiological data. The TDI for coumarin was derived to be $0.1 \mathrm{mg}$ (milligrams) of coumarin per kg of bodyweight and day and represents the amount that a person can ingest daily over a lifetime without appreciable health risk. This means that an adult with a body weight of $60 \mathrm{~kg}$ can consume $6 \mathrm{mg}$ of coumarin every day for the rest of their life without any noticeable health impairment. The European Food Safety Authority (EFSA) has calculated the same value in its assessment of coumarin. Data of food monitoring shows that Cassia cinnamon on average contains approximately $3000 \mathrm{mg}(3 \mathrm{~g})$ of coumarin per $\mathrm{kg}$ of cinnamon. However, the highest measured levels were as high as $10000 \mathrm{mg} / \mathrm{kg}$. An adult with a body weight of $60 \mathrm{~kg}$ reaches the TDI by consuming about $2 \mathrm{~g}$ of Cassia cinnamon per day. A small child with a body weight of $15 \mathrm{~kg}$ reaches its TDI by ingesting about $0.5 \mathrm{~g}$ of Cassia cinnamon. For small children, the TDI would be reached if they ate $30 \mathrm{~g}$ of cinnamon cookies (about 6 small cinnamon cookies) or $100 \mathrm{~g}$ of ginger bread cake every day, provided that no other coumarin exposure from other sources occurs. As with other foods, the BfR recommends consumption in moderation. Those who frequently use large amounts of cinnamon as a spice in their home cooking, for example for rice pudding with sugar and cinnamon, should make sure that they use Ceylon cinnamon which is low in coumarin [2].

In anglophone countries and their former colonies, rather than in other European countries, ginger is widely used as a spice. The slightly sweet and zesty heat is essential in Southern Asian cuisine. The spicy after burn gives the 
special flavor to Christmas bakery. The rhizomes of Zingiber officinale are cultivated in many tropical countries, from India via Australia to the Caribbean. In 500 B.C., Confucius is reported to have stated that he is never without ginger when he eats [3]. The rhizomes contain essential oils with a very complex composition of sesquiterpenes such as zingiberene, ar-curcumen, $\beta$-bisobolol, farnesene, monoterpenes such as campher, geranial, neral and linallol as well as non-volatile arylalkanes such as gingeroles, shogaoles and gingerones. Beside its use as a spice, ginger has a long tradition in medical use for treatment of dyspepsia, appetizing agent, as anti-emetic, for its anti-inflammatory effect on peptic ulcers and in the treatment of certain parasitic infections (e.g. schistosomiasis) [1]. In the contest of reproductive medicine, the use of ginger to relieve pregnancy nausea and vomiting is well documented. It is also found effective in the treatment of motion sickness and post-operative nausea. The anti-emetic effect is attributed to an increase in gastric tone and peristalsis via anticholinergic and anti-serotonergic pathways [4]. Although, the use of ginger is not without risk. The daily dose in pregnancy should not exceed $4 \mathrm{~g}$, due to uterine stimulating effects and caution should be applied when using ginger together with hypoglycemic drugs, such as insulin and metformin, with anti-platelet treatment, such as aspirin, with blood pressure lowering drugs such as nifedipine and with proton pump inhibitors such as omeprazole due to increased production of gastric acid. For metformin, insulin, aspirin and nifedipine synergistic effects are described [4].

Cardamon, the dried fruits of Elettaria cardamomum, origin just as ginger from a plant of the Zingiberaceae family, native to the moist mountain forest in Southwest India. Today the plant is also cultivated in Sri Lanka and Guatemala. The seeds contain 3-7\% essential oils, e.g. 1,8-cineol, and $\alpha$-terpinylacetate, as well as linalool, linalylacetate, sabinen, $\alpha$-pinen, $1-2 \%$ fatty oils, sugar, protein, manganese and iron. The most pronounced health benefits are seen in the treatment of dyspeptic disorders and loss of appetite [1]. One ingredient that certainly should not be forgotten in this context is honey. The beneficial effects honey is at least known since ancient Egyptian times. And due to its high sugar content and antibacterial properties, samples have preserved over centuries. The saccharose collected by bees is cleaved into invert sugar in the insect's stomach, is mixed with pollen, dehydrated and thickened. Honey contains about 50-85 \% invert sugar, $1-8 \%$ saccharose, gluconic acid, proteins, enzymes such as glucohexidase, phosphatase, invertase, diastase and catalase, vitamins (B1, B2, B6), flavonoids, minerals and antibiotic active compounds such as pinocembrin [1]. Along with its use as sweetener, honey is traditionally used as secretolytic in respiratory diseases and in wound treatment and topically in cosmetics.

Having the effects of the most abundant spices of the season in mind, the step to "Lebkuchen" (from the German leben $=$ to live), peppernuts (in medieval time all exotic spices were often summarized as "pepper") and ginger bread is a logic consequence. As already said, exotic spices such as cinnamon, ginger, cloves, cardamom were rare and mostly unaffordable. Especially in the old European monasteries, the monks and nuns used to bake durable cakes and cookies containing spices, nuts and honey with positive health effects which could be stored. The goods were regarded as medicines. Sometimes it was the anti-inflammatory effect of the ingredients, sometimes it was simply the appetizing and nutritional effect that helped patients to recover.

Dried fruits are a wonderful source of tasty flavours, antioxidants, minerals and vitamins. No wonder that mankind stored them for the winter season, when a natural supply of calories, vitamins and minerals was limited and the food supply was scarse and often monotonous. And it comes from this habit, that traditional Christmas bakery is stuffed with dried raisins, cranberries, apricots, etc. Especially cranberries (Vaccinium macrocarpon from the Ericaceae family) have a long and safe tradition of use during pregnancy and lactation for their properties to prevent and cure urinary tract infections due to phenolic compounds such as oligomere proanthocyanidines [4]. Also in this case, caution should be applied when using cranberry juice or fruits in co-treatment with the pain reliever diclofenac or the anxiolytic and sedative diazepam, as in vitro testing displayed an inhibition of CYP2C9 which can lead to increased blood levels of drugs which are metabolized by this enzyme. Clinical research yielded contradictory results.

One more plant family, to my opinion, has to be included, even when its use is not strictly season related, the Alliaceae. When it comes to onions (Allium cepa), garlic (Allium sativum), leek (Allium porrum), shallot (Allium ascalonicum), chives (Allium schoenoprassum), ramson (Allium ursinum), its versality in culinary use and medical properties is astonishing. The culinary variants were originally native to the Mediterranean region and the Middle east but are cultivated now worldwide. The pungent, eye watering smell is created by the action of the enzyme alliinase after cell walls are severed by cutting, which hydrolyzes sulphur-containing precursors (alliin) to pyruvic acid and alkylsulphenic acid, the latter being subsequently converted into allicin, diallylsulfid and ajoen. A little hint to reduce the eye irritating effect: wash the onions with warm water and cut them while very moist. The water dissolves most of the volatile irritating compounds. The vegetables are rich in alkylcysteinsulfoxides such alliin and its derivatives, essential oils, flavonoids, phenolic compounds and vitamins. Beside their culinary use, the plant species are valued for the therapeutic properties against loss of appetite, enhancement of digestion, the positive effect in the treatment of cough and sore throat, the long-time blood-pressure lowering effects, additive effects in the prevention of arteriosclerosis and supportive action in diabetes treatment. Topical use of onion slices includes neutralizing certain insect poisons after stinging and anti- 
bacterial effects $[1,3]$. In traditional medicine, a diet rich in onions and garlic is used to treat hemorrhoids due to the fiber content, the slightly bloating effect and the anti-inflammatory/ anti-bacterial properties.

When it comes to get together with friends and families, a choice of three beverages is almost always present: coffee (especially Coffea arabica and C. canephora, Rubiaceae), tea (Camellia sinensis, Theaceae) or cacao (Theobroma cacao, Sterculiaceae). All of the above plants share as pharmacologically active ingredients the methylxanthines, based on a purine alkaloid structure. The methylxanthines caffeine (1,3,7-trimethylxanthine), theobromine (3,7-dimethylxanthine) and theophylline (1,3-dimethylxanthine) are also found in cola seeds and mate. The annual worldwide consumption of caffeine is estimated to be $120000 t$, with coffee consumption accounting for about $50 \%$ and tea with about $51500 \mathrm{t}$ of the total amount. Methylxanthines have various pharmacological actions. In therapeutic doses, the main pathway is the adenosine receptor antagonism (via $\mathrm{A} 1$ and $\mathrm{A} 2$ receptors). In higher doses, an inhibition of the phosphodiesterase occurs, liberation of catecholamines, binding to benzodiazepine receptors, prostaglandin antagonism through inhibition of the cyclooxygenase and influence on intracellular calcium fluxes $[5,6]$. The central nervous stimulatory effects, bronchodilation and cardiovascular effect are mediated mainly be the adenosine antagonism, which is specially pronounced in 1-methylxanthines (caffeine, theophylline). The cardiac action of caffeine (positive ionotropic, positive chronotropic, positive dromotropic and positive bathmotropic) is short term, not very pronounced and undergoes a tolerance phenomenon. Caffeine also leads to dilatation of the coronary vessels but to restriction of cerebral vessels, the blood pressure can increase over a short period of time, but here also a certain degree of tolerance mechanisms is seen. The smooth musculature of the bronchi becomes relaxed, the secretion of gastric fluids is increased and lipolysis is stimulated. Overdosing on caffeine $(>500-750 \mathrm{mg} / \mathrm{d}$ in adults, much less in children) and theophylline (plasma levels $>15 \mu \mathrm{g} / \mathrm{ml}$ ) can lead to nausea, tachycardia, tremor, head ache and arrhythmias. Caffeine is easily and completed absorbed after oral intake and distributed among the body fluids, so that blood, urine and breast milk reach about the same concentrations. The biological half-life is about 4-5 h, with a slightly shorter life of $3 \mathrm{~h}$ in smokers. During pregnancy, the half-life increases to about 8-10h. Newborn do not have the necessary metabolic properties yet and the half-life may not be calculated in hours but rather days (up to 90h) [5]. While a suspected increase in the incidence of miscarriage after high coffee consumption during pregnancy was not confirmed, several studies did show a slight increase in the risk of intrauterine growth restriction (IUGR) after maternal caffeine consumption of more than $150 \mathrm{mg} / \mathrm{d}$, with equals about 2 cups of coffee. A review of the literature in 2000 demonstrated no increased risk for in utero growth [4]. The hypothesis, that theobromine could reduce the rate of preeclampsia, has not been confirmed.

While caffeine is mostly used as a stimulant, theophylline has its most pronounced pharmacological option in bronchodilatation in the treatment of asthma and apnoe in premature babies [6]. And do not underestimate the stimulatory effect of cacao in chocolate.

Enjoying a balanced diet with highly varying components usually is sufficient for a supply of all vital vitamins and minerals. Food supplements might not be necessary. Only few groups are at a higher risk for nutrient deficiencies, including pregnant women (iron, iodine, and folic acid), elderly or people with poor or restricted diets. Please be aware, that food supplements are by no means a replacement for a healthy diet.

Unfortunately, the holiday season and alcohol consumption are highly associated. Alcohol is the most widely used recreational drug and the most abundant teratogen. As a reproductive toxicologist it is painful to walk the streets of my city and see once so often children with the typical craniofacial morphology of the Fetal-Alcohol-Syndrome (FAS). Those children not displaying the phenotypic characteristics may still be highly affected due to fetal exposure and its detrimental effects on intellectual, physical, behavioral, social and emotional development. FAS are the most abundant reason for congenital mental impairment, it's irreversible but completely avoidable $[7,8]$. Research into the epidemiology, embryological pathways and prevention of what is now commonly referred to as Fetal Alcohol Spectrum Disorders (FASD) has increased dramatically over recent years. The global prevalence of FASD among children and youth is to be 7.7 per 1000 population (95\% CI, 4.9-11.7/1000). The WHO European Region had the highest prevalence (19.8/1000; 95\% CI, 14.1-28.0/1000), and the WHO Eastern Mediterranean Region had the lowest (0.1/1000; 95\% CI, 0.1-0.5/1000). Of 187 countries, South Africa was estimated to have the highest prevalence of FASD at 111.1 per 1000 population, followed by Croatia at 53.3 per 1000 population and Ireland at 47.5 per 1000 population [9]. The incidence is reflected by cultural background. Where alcohol consumption is common and largely accepted, the emotional hurdle for women to drink during pregnancy is much lower as in regions where, by cultural and/or religious tradition, alcohol is not part of "a normal diet" or social life. Although the embryo- and fetotoxic effects of alcohol are dose dependent, no "safe" level of alcohol consumption in pregnancy has been defined. Besides recreational drinking, the use of alcohol-containing medications (with concentrations $>10 \%$ ), although not comparable with abuse, should be avoided during pregnancy [4]. So next time the urge for mulled red wine or spiced hot cider emerges, why not try to surrogate with hot red grape juice or apple juice flavored with cinnamon, cloves, ginger and honey? 
Due to the abundant information on the risks of overweight and obesity, I would like to limit my remarks to a very few sentences towards pre- and postnatal consequences. Since the publication of David Barkers hypothesis of the Developmental Origin of Health and Disease (DOHaD) a multitude of associations between fetal developmental conditions and later onset of disease in adulthood has been confirmed. The first associations stemmed from cohort studies of populations prenatally exposed to malnutrition and famine (the Helsinki Birth Cohort born 1934-44, the Dutch famine 1944-45, the Chinese famine 1959-62) and displayed an increased risk for later development of cardiovascular disease, hypertension, type 2 diabetes, metabolic syndrome and psychosocial behavior [10-16]. These diseases originate from permanently altered gene expression through programming in the developing fetus when undernourished. Similar mechanisms step in during maternal over nutrition, which often contributes to obesity and/or diabetes and may result in macrosomia and enhanced cardiometabolic risk in the offspring. The children of obese or diabetic mothers are relatively more prone to develop obesity, insulin resistance, diabetes, and hypertension. It seems that, particularly, a maternal highfat/junk food diet may be detrimental for vascular health in the offspring. Fetal exposure to excessive levels of saturated fatty and/or n- 6 fatty acids, sucrose, fructose and salt, as well as a maternal high glycemic index diet, may also contribute to later enhanced cardiometabolic risk [17]. With the increasing obesity pandemic, the future consequences on chronic disease can only be estimated. The regions with the largest absolute increase in the number of children and adolescents with obesity were East Asia, the Middle East and North Africa, South Asia, and the high-income English-speaking region. The worldwide number of adult women with obesity increased from 69 (95\% CrI 57-83) million in 1975 to 390 (95\% CrI 363-418) million in 2016; the number of men with obesity increased from 31 (95\% CrI 24-39) million in 1975 to 281 (95\% CrI 257-307) million in 2016. An additional 213 million children and adolescents and 1.3 billion adults were in the overweight range, but below the threshold for obesity. Prevalence of obesity in children, adolescents was about $20 \%$ or more in several countries in Polynesia and Micronesia, the Middle East and north Africa, the Caribbean, and the USA [18].

In this context, some more behavioral aspects seem to be worth mentioning. Cold and fresh air: For those of us living in the Northern hemisphere where the festive season falls into winter, don't be afraid to face the cold. Bundle up, put some sunscreen on your face and go outside for a while. It has not only positive psychological effects in terms of fighting the winter blues with light, it also pushes the immune function and even as little as $15 \mathrm{~min}$ sunlight on your face are sufficient to boost your indigenous vitamin D production. People spending a sufficient time in the fresh air every day suffer from less episodes of colds. The enhancement of vitamin D production furthermore promotes healthy bones growth and prevents osteoporosis due to maintenance of physiological blood calcium levels and is known to further promote a healthy immune reaction. A number of auto-immune diseases are associated with vitamin D deficiency. The dietary supply with vitamin D only accounts to $10-20 \%$ of the amount, the majority is built internally through precursors and sunlight UV-B exposure [19].

As everybody should be familiar with the dangers of open fires and candles, I would like to point out that oil lamps pose another risk. For decades, serious poisonings, sometimes fatal, have occurred upon ingestion/inhalation of lamp oils by children. Even small amounts of paraffin-based oils that enter the lung can cause life-threatening chemical pneumonia. Despite repeated warnings, serious accidents involving lamp oils and grill lighter fluids happened, as children drank them inadvertently. This danger is increased even more as these fluids are often colored and scented and children were attracted by curiosity. Today, after new labelling requirements stating "Just a sip of lamp oil - or even sucking the wick of lamps - may lead to life-threatening lung damage" and the obligation to sell lamp oils and grill lighter fluids on paraffin basis only in black, opaque containers not exceeding one liter, the incidence of these poisonings declined [20].

For many, the decorated Christmas tree certainly belongs into the festive season. The tradition started in late medieval Europe, where maidens and menials lived in their master's home, far away from their families. Around Christmas, wooden tree-like structures were erected in the living room and decorated with cookies, dried fruits and bread. The tree was shaken and the servants could pick up whatever detached. Usually these were the only presents they got. The idea of chopping down a real tree, bringing it inside and decorating it, arose much later, most likely in the late 18th century, in the homes of the wealthy. Today, mostly pine and spruce trees are used (Pinus sylvestris, Abies alba, Abies nordmanniana). The aromatic scent comes from the essential oils of the fresh needles and twigs, containing $10-50 \% \alpha$-pinen, up to $20 \%$ 3 -caren, up to $12 \%$ camphen, $10-25 \% \beta$-pinen and limonen, myrcen and terpinols [1]. The inhalation of the essential oils is used since centuries for the treatment of respiratory diseases and topical use of alcoholic extracts for the relieve of muscle and neuropathic pain.

To sum up what was said; I would like to cite the honorable Paracelsius (Theophrastus Bombast von Hohenheim, 14931541): "All things are poison, and nothing is without poison, the dosage alone makes it so a thing is not a poison." So, whatever you do, do it in moderation and enjoy the festive season. Celebrate good food. And never underestimate the positive effects of tender loving care. Enjoy your holidays! 


\section{References}

1. Hiller K, Melzig MF (2010) Lexikon der Arzneipflanzen und Drogen, $\left(2^{\text {nd }}\right.$ edn) Spektrum Akademischer Verlag, Heidelberg, Germany, pp. 659.

2. http://www.bfr.bund.de/cm/349/faq-on-coumarin-in-cinnamonand-other-foods.pdf

3. Johnson RL, Foster S, Low Dog T, Kiefer D (2012) Guide to Medicinal Herbs: The World's Most Effective Healing Plants. National Geographic Society, Washington DC, USA, pp. 383.

4. Schaefer C, Peters P, Miller RK (2015) Drugs during pregnancy and lactation. Treatment options and risk assessment, ( ${ }^{\text {rd }}$ edn). Elsevier, Amsterdam, USA pp. 892.

5. Gilbert SG (last updated 2017): A Small Dose of Toxicology - Caffeine. Healthy World Press.

6. Teuscher E, Lindequist U (1994) Biogene Gifte. Biologie, Chemie, Pharmakologie. ( $2^{\text {nd }}$ edn). Gustav Fischer, Stuttgart, pp. 681

7. Spohr HL (2006) Das klinische Bild des Fetalen Alkohol-Syndroms - Fetal Alcohol Spectrum Disorder (FSAD), In: Bergman, Spohr, et al. (Eds.) Alkohol in der Schwangerschaft - Häufigkeit und Folgen. München: Urban \& Vogel. pp. 83-92.

8. Feldmann R (2006) Psychopathologie bei Kindern und Jugendlichen mit Fetalem Alkohol-Syndrom. In: Bergman/Spohr/Dudenhausen (Hrsg.). Alkohol in der Schwangerschaft - Häufigkeit und Folgen. München: Urban \& Vogel, pp. 93-101.

9. Lange S, Probst C, Gmel G, Rehm J, Burd L, et al. (2017) Globa Prevalence of Fetal Alcohol Spectrum Disorder Among Children and Youth: A Systematic Review and Meta-analysis. JAMA Pediatr 171(10) 948-956.

10. Barker DJP (1999) Fetal origins of cardiovascular disease. Ann Med 31(suppl 1): 3-6.
11. Barker DJ (2002) Fetal programming of coronary heart disease. Trends Endocrinol Metab 13(9): 364-368.

12. Painter RC, Roseboom TJ, Bleker OP (2005) Prenatal exposure to the Dutch famine and disease in later life: an overview. Reprod Toxicol 20(3): 345-352.

13. Barker DJ, Thornburg KL (2013) The obstetric origins of health for a lifetime. Clin Obstet Gynecol 56(3): 511-9.

14. Susser E, St Clair D (2013) Prenatal famine and adult mental illness: interpreting concordant and discordant results from the Dutch and Chinese Famines. Soc Sci Med 97: 325-330.

15. Lunde ER, Washburn SE, Golding MC, Bake S, Miranda RC, et al. (2016) Alcohol-Induced Developmental Origins of Adult-Onset Diseases. Alcohol Clin Exp Res 40(7): 1403-1414

16. Wang N, Wang X, Li Q, Han B, Chen Y, et al. (2017) The famine exposure in early life and metabolic syndrome in adulthood. Clin Nutr 36(1): 253-259.

17.Szostak-Wegierek D (2014) Intrauterine nutrition: long-term consequences for vascular health. Int J Womens Health 6: 647-656.

18. NCD Risk Factor Collaboration (NCD-RisC) (2017) Worldwide trends in body-mass index, underweight, overweight, and obesity from 1975 to 2016: a pooled analysis of 2416 population-based measurement studies in 128.9 million children, adolescents, and adults. Lancet 390(10113): 2627-2642.

19. Wuertz C, Gilbert P, Baier W, Kunz C (2013) Cross-sectional study of factors that influence the 25-hydroxyvitamin D status in pregnant women and in cord blood in Germany. Br J Nutr 110(10): 1895-1902.

20. BfR (2011).

\section{Your next submission with Juniper Publishers will reach you the below assets}

- Quality Editorial service

- Swift Peer Review

- Reprints availability

- E-prints Service

- Manuscript Podcast for convenient understanding

- Global attainment for your research

- Manuscript accessibility in different formats ( Pdf, E-pub, Full Text, Audio)

- Unceasing customer service

Track the below URL for one-step submission

https://juniperpublishers.com/online-submission.php 